\title{
Conservative management of a late rectal perforation following cold biopsy polypectomy
}

Bowel perforation is a rare complication of endoscopic polypectomy [1]. It may result from excessive stretching of the bowel wall during the movements of the endoscope, barotrauma, or as a direct result of endoscopic therapy or tissue sampling [1]. We report the case of a 55-year-old man with a familial history of colon cancer and previous endoscopic removal of adenomas in the descending colon who underwent a follow-up colonoscopy. The examination, which was easily carried out up to the cecum, revealed a 4-mm sessile polyp in the rectum $(8 \mathrm{~cm}$ from the anal verge), removed with cold biopsy. The patient presented to the emergency room 2 days later with fever $\left(39^{\circ} \mathrm{C}\right)$, and severe abdominal pain and distension. Hematological investigations showed a white cell count of $16700 / \mu \mathrm{L}$ with granulocytosis (95.3\%) and a C-reactive protein level of $28.68 \mathrm{mg} / \mathrm{dL}$. Physical examination revealed tenderness in the lower abdomen. No free air was seen on both abdominal and chest radiographs. The patient then underwent urgent computed tomography (CT) of the abdomen, which showed rectal perforation with a collection in the perirectal space ( $\nabla$ Fig.1a) without pneumoperitoneum ( $\bullet$ Fig. 1 b). The patient improved with conservative management that included bowel rest and intravenous antibiotics and was discharged 1 week later. After 1 month a repeat abdominal CT scan showed normal findings ( $\bullet$ Fig. 2a, b).

Cold biopsy forceps removal is the simplest method for polypectomy of small colorectal polyps [2]. The advantages of cold biopsy polypectomy include avoidance of the risks associated with electrocautery and an almost negligible risk of colonic perforation [3]. To the best of our knowledge, this is the first case report of a late rectal perforation following cold polypectomy with biopsy forceps, which was managed conservatively. This management option was chosen and was successful because the perforation was very small and occurred below the pelvic peritoneal reflection, so that the extravasation remained extraperitoneal.
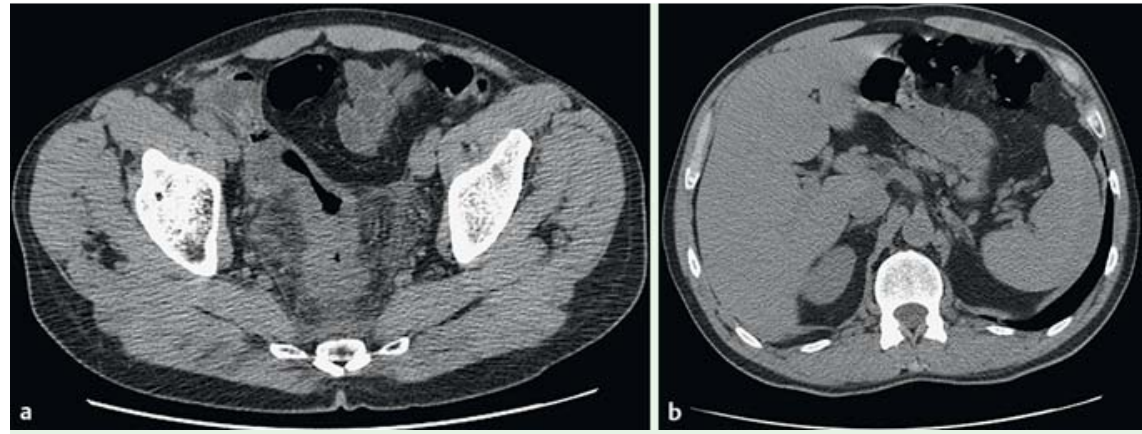

Fig. 1 Computed tomography (CT) in a 55-year-old man presenting with fever and severe abdominal pain and distension following cold biopsy polypectomy 2 days earlier. a View showing the rectal perforation. b There was no pneumoperitoneum.
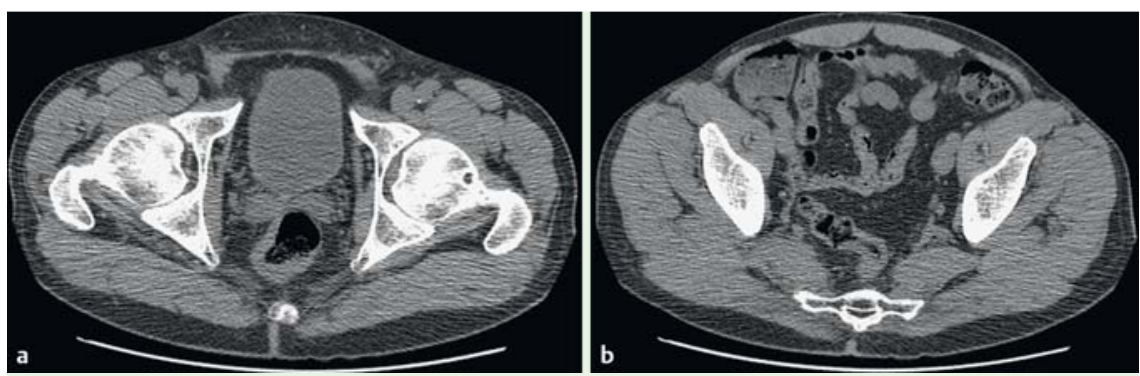

Fig. 2 a, b Computed tomography images at follow-up 1 month showing complete resolution of the perforation.

Endoscopy_UCTN_Code_CPL_1AJ_2AC

Competing interests: None

\section{Luigiano', F. Ferrara², S. Miraglia', C. Favara ${ }^{1}$, C. Fabbri ${ }^{2}$, G. La Ferrera ${ }^{1}$, C. Virgilio ${ }^{1}$}

${ }^{1}$ Unit of Gastroenterology and Digestive Endoscopy, ARNAS Garibaldi, Catania, Italy

2 Unit of Gastroenterology and Digestive Endoscopy, AUSL Bologna Bellaria-Maggiore Hospital, Bologna, Italy

\section{Refereces}

1 Panteris V, Haringsma J, Kuipers EJ. Colonoscopy perforation rate, mechanisms and outcome: from diagnostic to therapeutic colonoscopy. Endoscopy 2009; 41: $941-951$

2 Hewett DG, Rex DK. Colonoscopy and diminutive polyps: hot or cold biopsy or snare? Do I send to pathology? Clin Gastroenterol Hepatol 2011; 9: 102-105

3 Rex DK. Preventing colorectal cancer and cancer mortality with colonoscopy: what we know and what we don't know. Endoscopy 2010; 42: 320-323

\section{Bibliography}

DoI http://dx.doi.org/

10.1055/s-0032-1325859

Endoscopy 2012; 44: E430

(c) Georg Thieme Verlag KG

Stuttgart · New York

ISSN 0013-726X

\section{Corresponding author}

\section{Luigiano}

Unit of Gastroenterology and Digestive Endoscopy ARNAS Garibaldi Nesima Hospital

Via Palermo 636

95122 Catania

Italy

Fax: +39-095-7595828

carmeluigiano@libero.it 